\title{
BMJ Open The use of triclosan-coated sutures to prevent surgical site infections: a systematic review and meta-analysis of the literature
}

\author{
Imran Ahmed, ${ }^{\oplus 1}$ Adam Jonathan Boulton, ${ }^{\odot 2}$ Sana Rizvi, ${ }^{2}$ William Carlos, ${ }^{2}$ \\ Edward Dickenson, ${ }^{3}$ NA Smith, ${ }^{4}$ Mike Reed ${ }^{5}$
}

To cite: Ahmed I, Boulton AJ, Rizvi S, et al. The use of triclosan-coated sutures to prevent surgical site infections: a systematic review and meta-analysis of the literature. BMJ Open 2019;9:e029727. doi:10.1136/ bmjopen-2019-029727

- Prepublication history and additional material for this paper are available online. To view these files, please visit the journal online (http://dx.doi. org/10.1136bmjopen-2019029727).

Received 12 February 2019 Revised 06 August 2019 Accepted 12 August 2019

Check for updates

(C) Author(s) (or their employer(s)) 2019. Re-use permitted under CC BY-NC. No commercial re-use. See rights and permissions. Published by BMJ.

${ }^{1}$ Clinical Trials Unit, University of Warwick, Coventry, UK

${ }^{2}$ Trauma and Orthopaedics, University Hospital Coventry, Coventry, UK

${ }^{3}$ Warwick Medical School, University of Warwick, Coventry, UK

${ }^{4}$ Clinical Sciences Research Laboratories, University of Warwick, Coventry, UK

${ }^{5}$ Trauma and Orthopaedics, Northumbria Healthcare NHS Foundation Trust, Northumberland, UK

Correspondence to Mr Imran Ahmed; imran.ahmed4@nhs.net

\section{ABSTRACT}

Introduction and objectives Surgical site infections (SSIs) represent a common and serious complication of all surgical interventions. Microorganisms are able to colonise sutures that are implanted in the skin, which is a causative factor of SSIs. Triclosan-coated sutures are antibacterial sutures aimed at reducing SSIs. Our objective is to update the existing literature by systematically reviewing available evidence to assess the effectiveness of triclosan-coated sutures in the prevention of SSIs.

Methods A systematic review of EMBASE, MEDLINE, AMED (Allied and complementary medicine database) and CENTRAL was performed to identify full text randomised controlled trials (RCTs) on 31 May 2019.

Intervention Triclosan-coated sutures versus nontriclosan-coated sutures.

Primary outcome Our primary outcome was the development of SSIs at 30 days postoperatively. A metaanalysis was performed using a fixed-effects model.

Results Twenty-five RCTs were included involving 11957 participants. Triclosan-coated sutures were used in 6008 participants and non triclosan-coated sutures were used in 5949. Triclosan-coated sutures significantly reduced the risk of SSIs at 30 days (relative risk $0.73,95 \% \mathrm{Cl} 0.65$ to 0.82 ). Further sensitivity analysis demonstrated that triclosan-coated sutures significantly reduced the risk of SSIs in both clean and contaminated surgery.

Conclusion Triclosan-coated sutures have been shown to significantly reduced the risk of SSIs when compared with standard sutures. This is in agreement with previous work in this area. This study represented the largest review to date in this area. This moderate quality evidence recommends the use of triclosan-coated sutures in order to reduce the risk of SSIs particularly in clean and contaminated surgical procedures.

PROSPERO registration number CRD42014014856

\section{INTRODUCTION}

Surgical site infections (SSIs) represent a common complication throughout all surgical procedures. ${ }^{1}$ It is estimated that SSIs account for $5 \%$ of all surgical complications $^{2}$ and $20 \%$ of all healthcare-associated infections. ${ }^{34}$ It is generally believed that the number of surgical procedures, particularly
Strengths and limitations of this study

Systematic nature of data collection and analysis.

- Largest review to date in this topic area.

- Analyses performed comparing different classifications of surgery, that is, clean, clean-contaminated, contaminated and dirty.

- Heterogeneous nature of included studies. For example, different age of participants, comorbidities and surgery type.

in elective orthopaedics, ${ }^{5}$ will increase over the next decade, therefore increasing the incidence of SSIs. SSIs are associated with prolonged hospital admission ${ }^{6}$ and increased morbidity and mortality. ${ }^{7-9}$ In addition to having a significant impact on patient care and experience, SSIs also add substantial costs to healthcare providers. It is estimated that SSIs cost UK healthcare services approximately $£ 61$ million in $2012^{10}$ and figures from the US highlight the extensive cost of SSIs with an estimated additional US $\$ 2300$ per case. ${ }^{11}$ Furthermore, Fleck et al found that the mean cost of treated a SSI following sternal wound incision was US\$11 200. ${ }^{12}$ These are conservative estimates as active surveillance of SSIs not routinely performed. ${ }^{6}$

Due to the wide ranging deleterious effects of SSIs and their treatment, particularly in the context of increasing numbers of surgical procedures, there is a clinical need to reduce the incidence of SSIs. SSIs are multifactorial with patient factors such as age, comorbidities including diabetes, and immunosuppression $^{713-15}$ contributing to their development, along with surgical factors. Many patient factors may not be optimised and hence research focus has been placed on surgical factors, including suture material.

SSIs may arise when bacteria colonise the suture material, ${ }^{16}$ creating a biofilm as it 
passes through the skin. ${ }^{17}$ This biofilm establishes an immunity from both antimicrobial treatment and the host immune system. ${ }^{6}{ }^{17}$ Once this biofilm develops there is an increased chance of a SSI developing. Research has shown bacteria may colonise monofilament and braided sutures. ${ }^{18-20}$ With this in mind, considerable work has been carried out since the 1950s with regards to coating suture material with an antimicrobial, including silver. ${ }^{21} 22$ Triclosan (polychlorophenoxyphenol) has been used for its antiseptic properties for many years in toothpaste and soap and has an established safety profile. ${ }^{5}$ Triclosan has been used to successfully coat the following sutures and gained US food and drug administration approval in 2002: braided polyglactan 910 (Vicryl Plus), poliglecaprone 25 (Monocryl Plus) and polydioxanone (PDS Plus).

In vitro and in vivo studies have shown the effectiveness of triclosan-coated sutures ${ }^{23-25}$ in killing bacteria associated with SSIs and inhibiting colonisation of suture material, with one study demonstrating a $66 \%$ reduction in bacterial colonisation. ${ }^{26}$ Since then a large number of randomised controlled trials (RCTs) have been performed with contrasting results of the effectiveness of triclosan-coated sutures in the prevention of SSIs. Subsequent meta-analyses have also produced conflicting results and hence the true effect remains unclear. $^{6}{ }^{727-32}$ The most recent and largest systematic review to date was performed by de Jonge et al and found triclosan-coated sutures significantly reduced the incidence of SSIs. ${ }^{32}$ This review searched the literature up until November 2015 and included 6462 patients from RCTs published in peer-reviewed journals as well as conference abstracts. Performing robust methodological appraisal of conference abstracts is not possible, they do not permit thorough risk of bias assessments, and as they have not undergone the formal journal peer-review process, they represent a potentially biassed and unreliable source of data. Since this review, a number of large, high-quality RCTs have been produced. ${ }^{33} 34$ Of note, a recent RCT of 2546 patients found that triclosan-coated sutures did not reduce the incidence of SSIs; a finding in contrast to the previous systematic review. ${ }^{32} 34$ This represents a substantial increase in the number of patients available for meta-analysis since the last review. As a result, we believe it is important to update the existing literature by performing a new, up to date, systematic review and meta-analysis to assimilate the current evidence and inform clinical practice. A new review should include a detailed risk of bias assessment and GRADE (Grading of Recommendations Assessment, Development and Evaluation) assessment of the quality of evidence.

This new systematic review and meta-analysis of the available literature aims to determine whether the use of triclosan-coated sutures reduces the incidence of SSIs in comparison to standard non-coated sutures.
PICOS (Participants, Intervention, Comparator, Outcomes and Study design) statement

The included population encompasses patients of any age and gender undergoing any surgical procedure utilising sutures to close the wound. The intervention studied is the use of triclosan-coated sutured and comparison is made with non-triclosan-coated sutures. The outcomes assessed are the rates of SSIs, including superficial and deep SSIs. This systematic review will only include RCTs.

\section{METHODS}

A systematic review of the available literature was conducted and is reported in accordance with the Preferred Reporting Items for Systematic Reviews and Meta-Analyses guidance. ${ }^{35}$ A protocol for this review was prospectively registered with PROSPERO.

\section{Search methods}

Electronic searches were conducted using OVID SP on the following databases: MEDLINE (1946-May Week 4 2019); Excerpta Medica Database (EMBASE) (1974-2019 May 31); Allied and Complementary Medicine (AMED) (1985-May 2019); and Cochrane Central Register of Controlled Trials (CENTRAL). A multipurpose search was performed for all terms and the search terms were: 'Triclosan', 'Anti-bacterial agents', 'Anti-infective agents, local', 'Coated materials, biocompatible', 'Biomimetic material', 'Sutures', 'Vicryl Plus', 'Monocryl Plus', 'PDS Plus', 'Surgical site infection', 'Surgical Wound infection'. The search was conducted on 31 May 2019. A copy of the search strategy can be seen in online supplementary file 1 .

\section{Selection of studies}

Two authors (IA and AJB) independently selected studies for inclusion. Any discrepancies were resolved by discussion with a third author (ED). Titles and abstracts were screened and full texts obtained for any studies of interest. The eligibility criteria were formed from the PICOS statement and registered on PROSPERO prior to undertaking the search. Only RCTs published in peer-reviewed journals presenting new data were included.

\section{Data extraction}

Data were independently extracted from eligible included studies onto predetermined forms by two authors (IA and AJB). Any discrepancies were then resolved following discussion between two authors (IA and AJB) and a third author. Data extracted included baseline patient characteristics, surgical procedures performed, number of centres, suture material, SSI diagnostic criteria, length of follow-up, routine prophylactic antibiotic use and number of SSIs. Data regarding superficial of deep SSI was extracted when possible. Information regarding randomisation, blinding, funding and country of origin was extracted. 


\section{Assessment of risk of bias}

Two authors (IA and AJB) independently appraised eligible studies according to the Cochrane Collaboration's risk of bias tool, resolving any discrepancies with a third author (ED) as necessary. ${ }^{36}$ Review Manager V.5.3 was used to generate the summary figures. The parameters used for 'other' sources of bias included source of funding and antibiotic regime.

Two authors (IA and AJB) independently assessed the quality of evidence. We used the GRADE considerations (study limitations, consistence of effect, imprecision, indirectness and publication bias) to assess the quality of the body of evidence. ${ }^{37}$ Decisions to upgrade or downgrade body of evidence have been clearly stated in the discussion.

Publication bias was assessed following construction of a funnel plot in order to identify the presence or absence of bias of this kind.

\section{Statistical analysis}

A fixed-effects model was used to calculate the predominant relative risk (RR) and the 95\% CIs of the studies included. Statistically heterogeneity was first assessed using a funnel plot and more formally using the $\mathrm{I}^{2}$ statistic ${ }^{36}$ Forest plots were then generated summarising the results of the meta-analysis using Review Manager V.5.3.

\section{Patient and public involvement}

Given the design of this study and the retrospective nature, patient and public members were not involved in the development and conduct of this review. With the aid of patient and public members we will produce lay summaries of the results available for patients.

\section{RESULTS}

The search revealed 357 records of possible relevance. No other sources of records were identified. Removal of duplicates left 249 records to be examined. Two hundred and nineteen records were excluded based on title and abstract screening. Thirty full texts were assessed for eligibility and 25 studies were included in the meta-analysis (see figure 1). ${ }^{2711333438-57}$

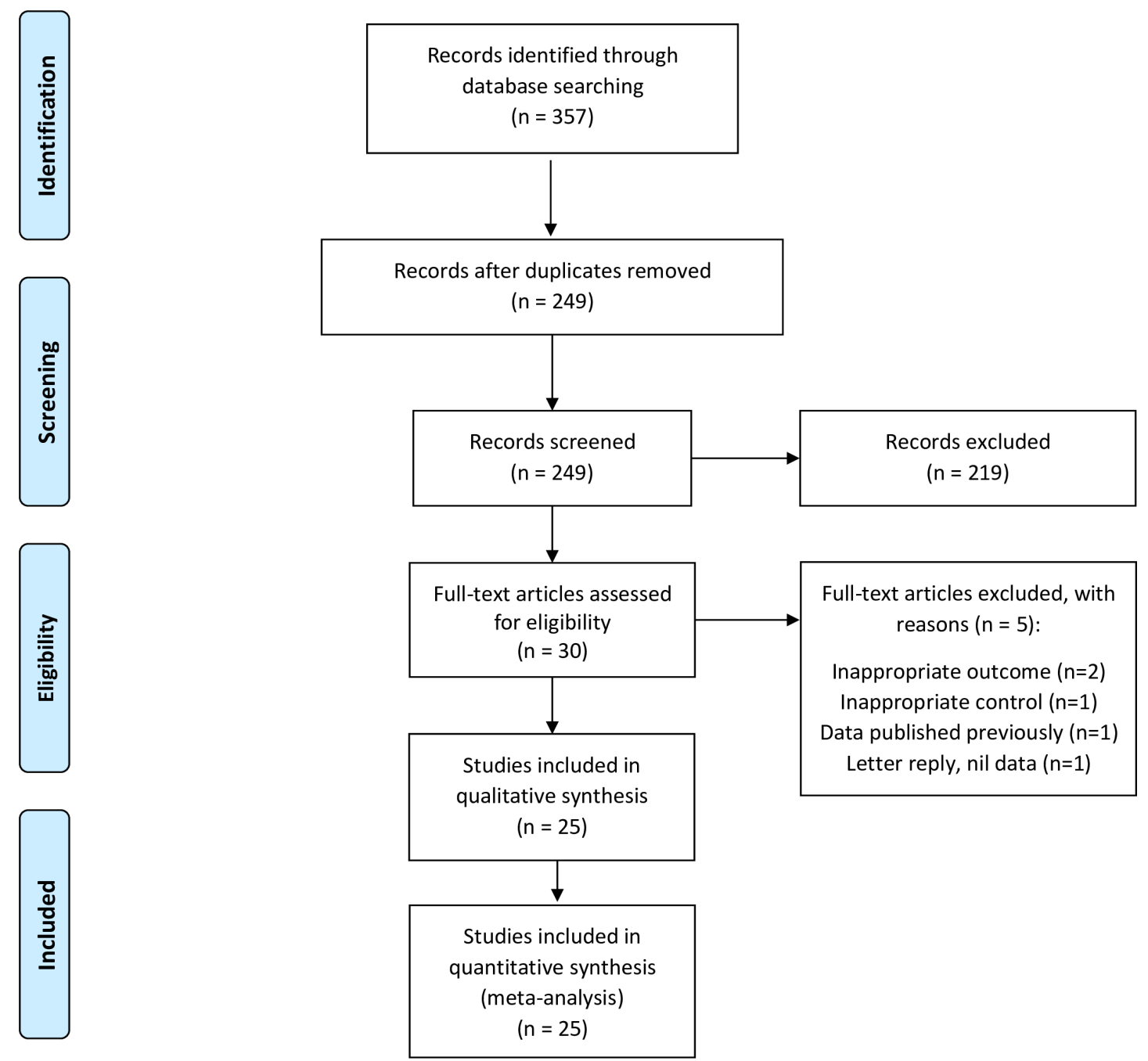

Figure 1 PRISMA flow diagram of search results. PRISMA, Preferred Reporting Items for Systematic Reviews and MetaAnalyses. 


\section{Study characteristics}

Study characteristics are summarised in table 1. Twenty-five RCTs were included in this review involving 11957 patients. $^{2} 711333438-57$ There were 6008 patients randomised to triclosan-coated sutures and 5949 patients to standard sutures. In studies which reported mean age, the mean age reported in 23 out of 25 studies was comparable between the two groups (54.8 vs 54.8). For the studies which reported gender $57 \%$ of the included patients were male. Eight studies were multicentre, with the remainder single-centre studies $(n=17)$. Vicryl was compared with Vicryl Plus in 12 studies, 11 34 39-41 43 46-495456 3 studies compared PDS versus PDS Plus, ${ }^{7} 38551$ study compared PDS II with PDS II Plus, ${ }^{44} 2$ study compared Monocryl against Monocryl Plus, ${ }^{45} 57$ compared Chinese silk with Vicryl Plus, ${ }^{53} 4$ studies compared Vicryl and Monocryl versus Vicryl Plus and Monocryl Plus ${ }^{33}$ 50-52 and 2 studies compared Vicryl and PDS versus Vicryl Plus and PDS Plus. $^{242}$

To define SSI, the centre for disease control (CDC) criteria were used by 18 studies, ${ }^{2} 711333441-444850-57$ clinical diagnosis or wound cultures was used by 3 studies studies, ${ }^{39} 4549$ and 4 did not provide explicit definitions. ${ }^{38404647}$ Seventeen studies used a follow-up duration of 30 days or 1 month or 4 weeks, ${ }^{2} 71133343841-4346495153-57$ 3 for 6 weeks, ${ }^{4850} 522$ for 2 weeks, ${ }^{44} 451$ for 80 days $^{40}, 1$ until discharge ${ }^{47}$ and 1 study did not specify a follow-up regime. ${ }^{39}$ Routine prophylactic antibodies were used in 19 studies, $2713438394244-51$ 54-57 no prophylactic antibiotics were used in 1 study, ${ }^{40} 1$ used prophylactic antibiotics in high-risk patients only, ${ }^{52} 1$ study used prophylactic antibiotics in $30 \%$ of participants ${ }^{33}$ and 3 did specify prophylactic antibiotic use. ${ }^{414353}$

\section{Surgical site infection}

The risk of developing SSI was significantly reduced in the triclosan group compared with the standard suture group (RR $0.73,95 \%$ CI 0.65 to 0.82 ). Heterogeneity was low to moderate $\left(\chi^{2}=24.66, \mathrm{p}=0 \cdot 21, \mathrm{I}^{2}=17 \%\right)$. There were 420 instances of SSI among 6008 patients in the triclosancoated suture group and 581 SSIs in 5949 patients in the standard suture group (see figure 2).

\section{Subgroup analysis}

Eight studies reported superficial and deep infections separately. ${ }^{2} 7333442465157$ There were 152/3507 cases of superficial SSI in the triclosan group and 164/3626 cases in the standard suture group, producing a meta-analysis risk ratio of 0.95 (95\% CI 0.72 to 1.25$)$. The risk of developing a deep infection was lower in the triclosan group when compared with the standard suture group; however, this was not significant (RR $0.77,95 \%$ CI 0.55 to 1.07). There were $61 / 3507$ cases of deep infections in the triclosan group and 85/3626 cases in the standard suture group (see figure 3 ).

Ten studies reported the incidence of SSI for clean surgery. ${ }^{33} 34 \quad 3943$ 49-53 56 Triclosan-coated sutures were associated with a significantly lower incidence of SSI
$(149 / 3029)$ when compared with standard sutures (230/1117) (RR $0.71,95 \%$ CI 0.58 to 0.88 ).

Six studies reported clean-contaminated surgery and there was no difference between the two groups (160/1540 vs 156/1504) (RR 1.02, 95\% CI 0.83 to 1.25). 2740424654

Four studies reported the incidence of SSIs in contaminated surgery. ${ }^{11475557}$ Triclosan-coated sutures were associated with a significantly lower risk of SSI (22/438) when compared with standard sutures (55/443) (RR 0.43, $95 \%$ CI 0.27 to 0.7$)$.

Two further studies reported the incidence of SSI for dirty surgery. ${ }^{45}$ There was no significant difference in the incidence of SSIs between the two groups of sutures (25/102 vs $35 / 105$ ) (RR $0.74,95 \%$ CI 0.46 to 1.18 ) (see figure 4).

\section{Risk of bias}

The results of the risk of bias screening can be seen on figure 2. The majority of studies had a clear randomisation sequence generation and allocation concealment using sealed envelopes. Five out of 25 (20\%) had high risk of selection bias, either because the randomisation method was not stated or a quasirandomisation method was used. Two further studies had a risk of selection bias due to unclear allocation concealment methods. Ten out of 25 studies $(40 \%)$ had high risk of performance and detection bias due to either absence of blinding of the participants and outcome assessors or the methods of blinding were not stated. Four out of 25 (16\%) were at high risk of other bias due to source of funding. One study had differences in antibiotic regime between the two groups, with one group not receiving any antibiotic prophylaxis.

The distribution of studies in the funnel plot was symmetrical. No evidence was found for publication bias in this analysis (figure 5).

Statistical heterogeneity was assessed using the $\tau^{2}(0.02)$ test and the $\mathrm{I}^{2}(17 \%)$ test, indicating there is low heterogeneity between the studies included in this review based on the recommendations in the Cochrane handbook.

\section{DISCUSSION}

This large systematic review of 25 randomised clinical trials included 11957 patients and there were 1001 instances of SSI. The subsequent meta-analysis supports the use of triclosan-coated sutures in reducing the risk of SSIs. We report a significantly lower risk of SSI when triclosan-coated sutures were used, compared with standard sutures in RCTs. Triclosan-coated sutures were used in a wide range of surgeries, including both adult and paediatric patients. The use of triclosan-coated sutures significantly reduced the risk of SSI in meta-analyses of clean surgery and also contaminated surgery. Further subgroup analysis revealed a non-statistically significant reduction in the risk of developing deep SSIs with triclosan-coated sutures. Triclosan-coated sutures appear to have no effect on the incidence of superficial SSIs. 


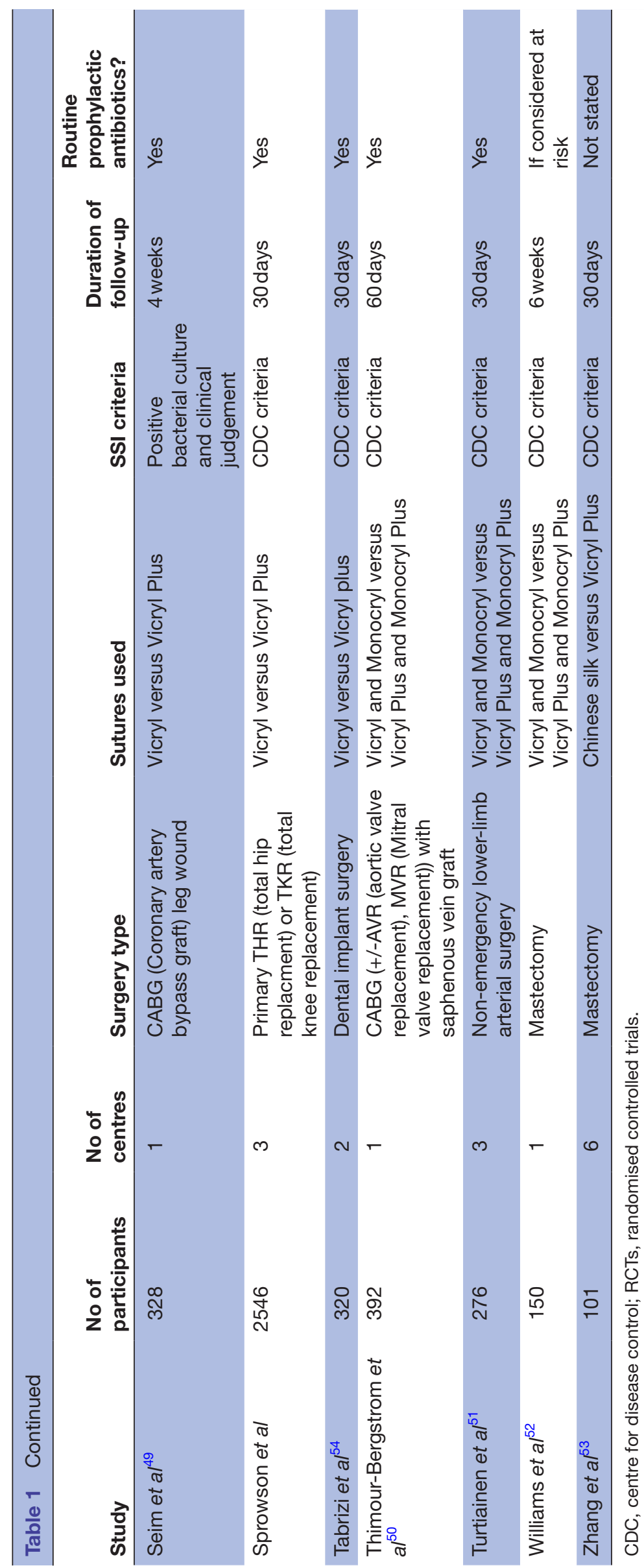

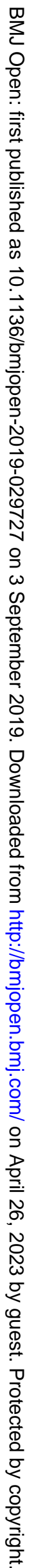




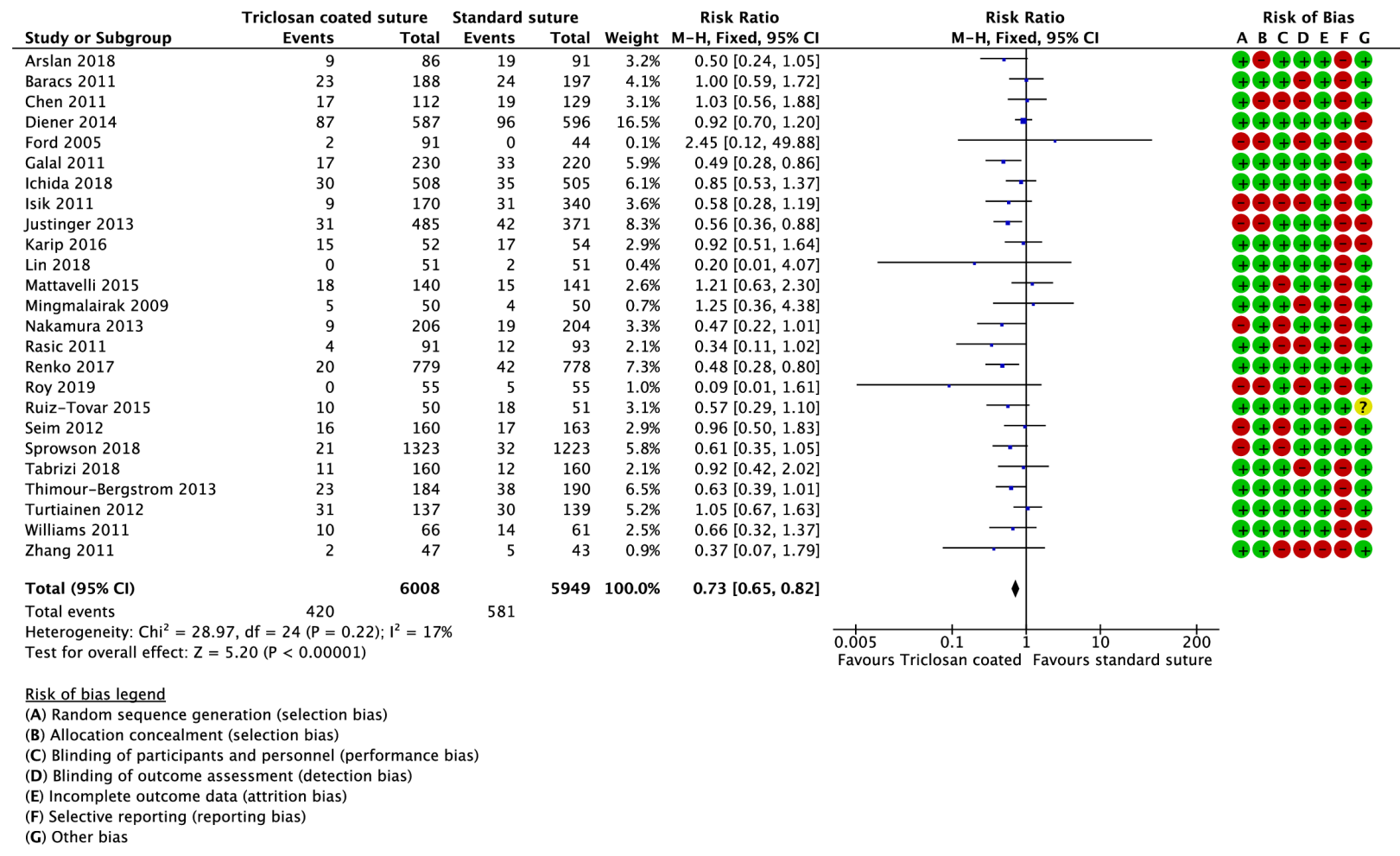

Figure 2 A meta-analysis of all studies included in this review. The forest plot is comparing triclosan coated sutures vs standard sutures on risk of developing surgical site infection. On the right of the figure a summary of our risk of bias assessment can be seen.

There have been 11 previous reviews in this topic area, the results of these reviews have been summarised in table $2 .{ }^{27} 28$ 30-32 58-63 Our results support the findings of Konstantelias et al who concluded that triclosan-coated sutures were associated with a significantly lower risk of SSI when compared with standard sutures. ${ }^{32} 61$ In addition, the authors concluded that triclosan-coated sutures significantly reduced the risk of SSI in clean, clean-contaminated and contaminated surgery; in agreement with our findings. ${ }^{61}$ de Jonge et al reported a meta-analysis of 21 RCTs including 6462 patients, also concluding that triclosan-coated sutures significantly reduced the risk of SSI compared with standard sutures. ${ }^{32}$ Five out of 11 reviews included a risk of bias assessment $^{2731325963}$ and only one review assessed the quality of evidence using the GRADE criteria. ${ }^{59}$

Risk Ratio

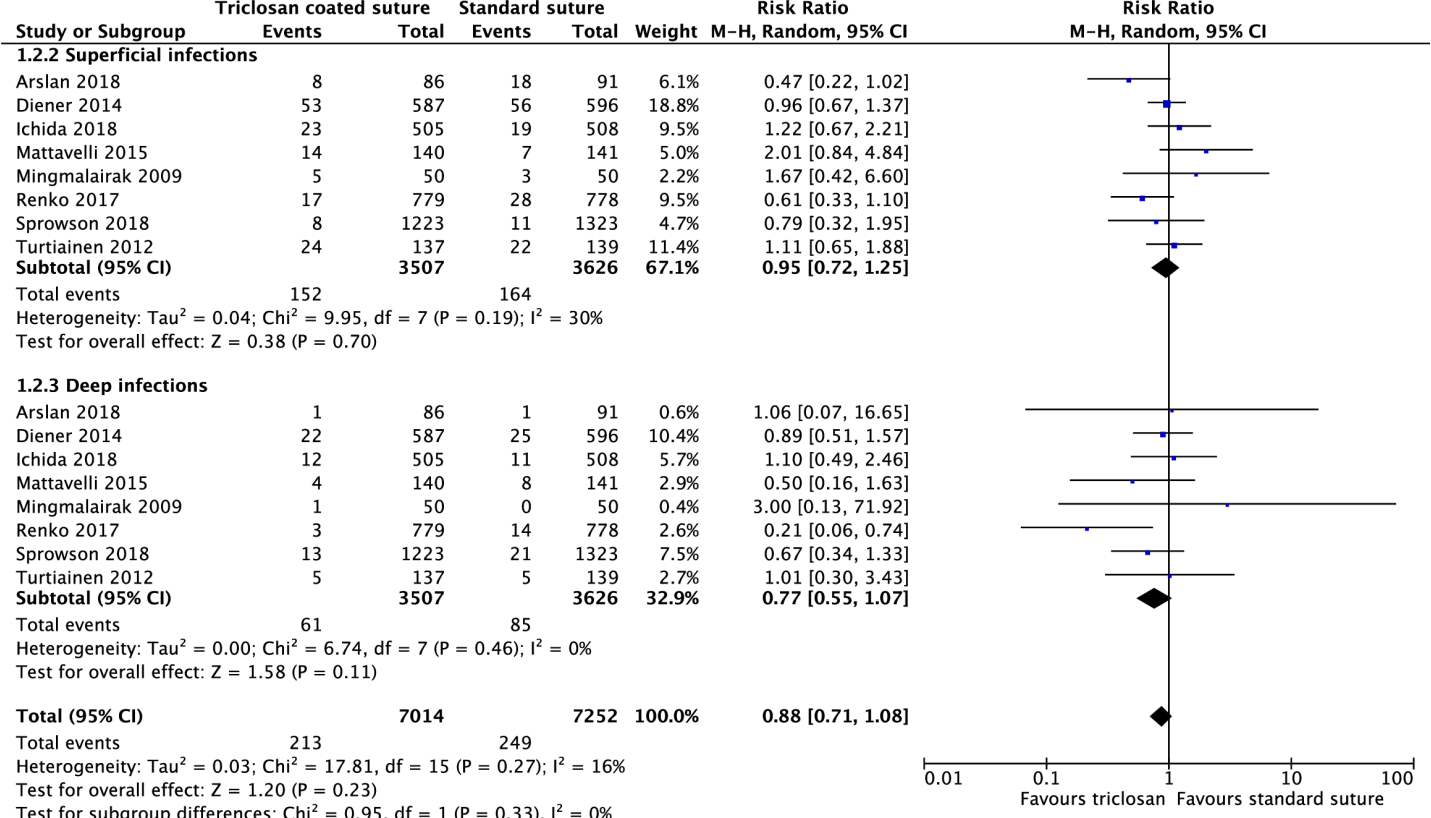

Figure 3 Subgroup analysis comparing triclosan coated sutures versus standard sutures on the risk of developing superficial and deep infections. 


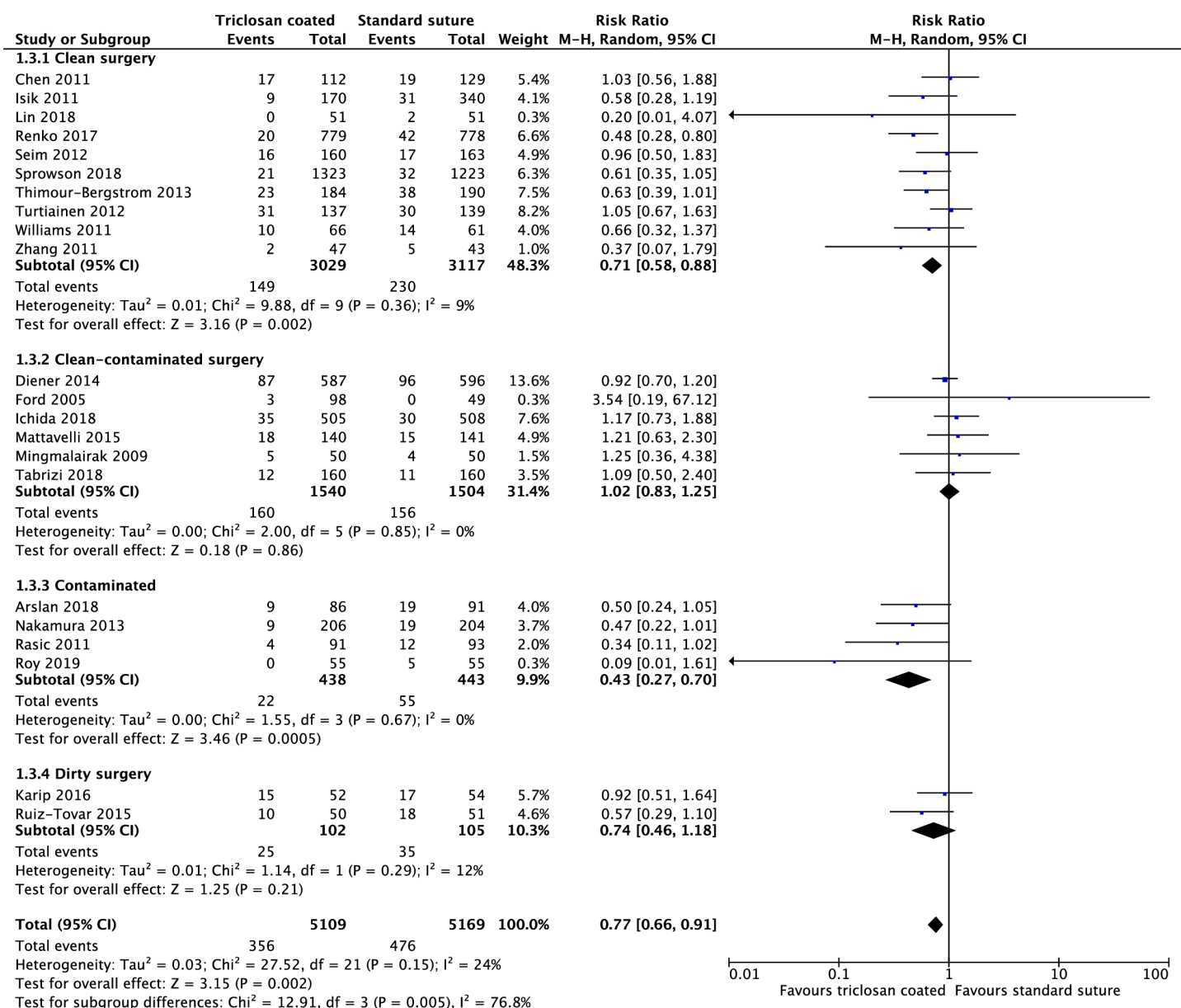

Figure 4 Subgroup analysis comparing triclosan coated sutures versus standard sutures on the risk of developing surgical site infections in clean, clean contaminated, contaminated and dirty surgery.

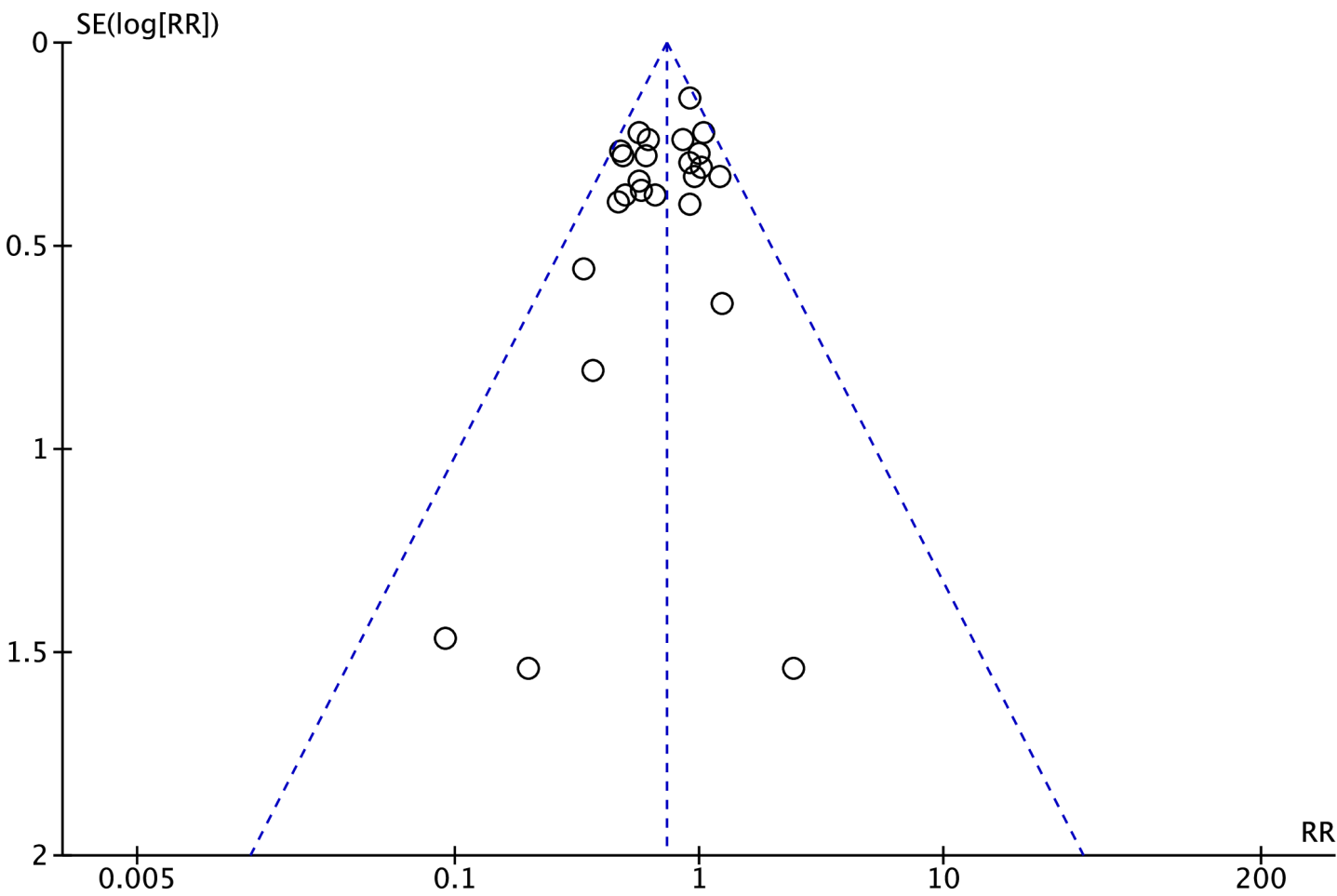

Figure 5 A funnel plot to assess for the presence of publication bias. 
Table 2 A summary of previous systematic reviews on this topic area highlighting number of studies, number of participants and key findings

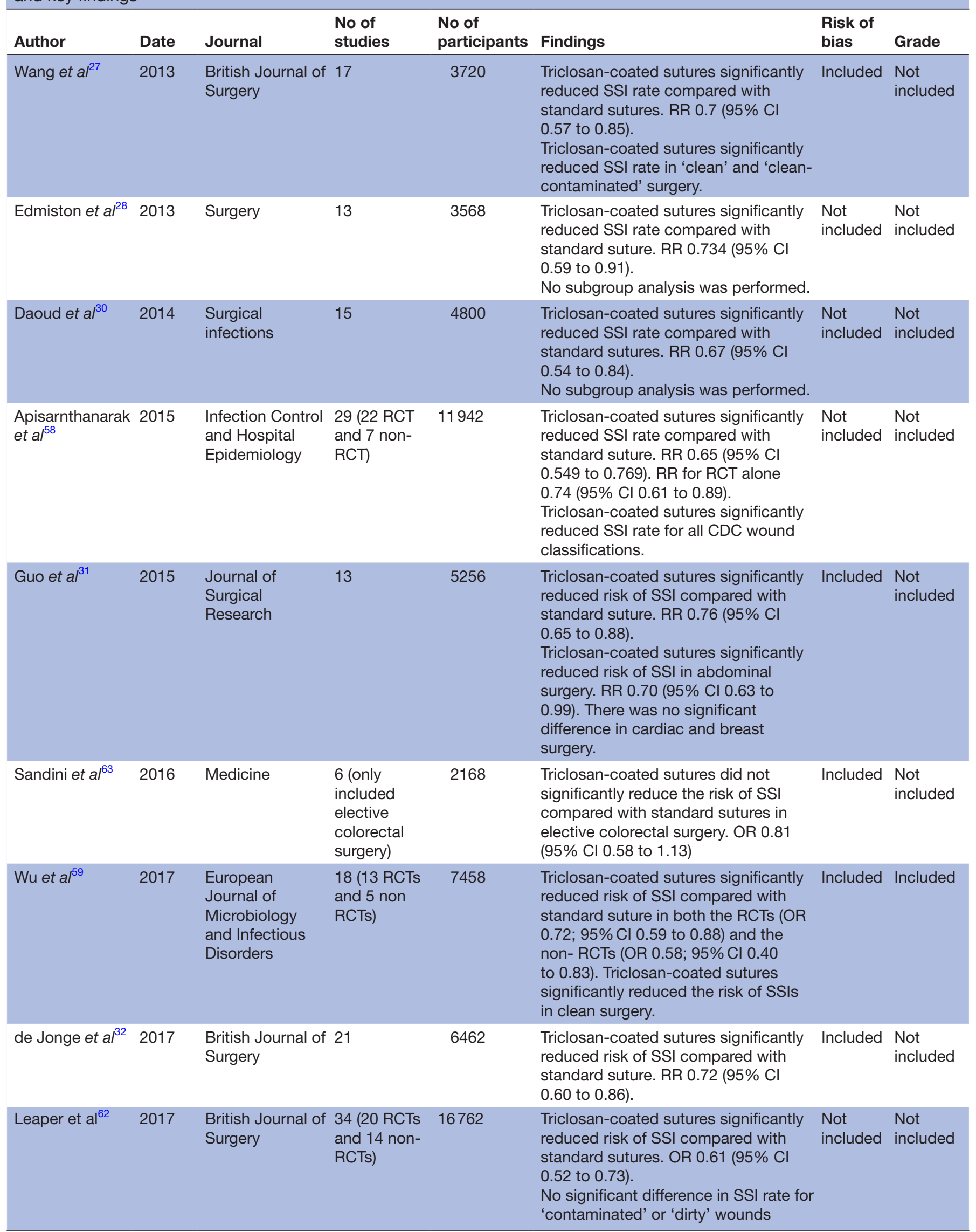

Continued 
Table 2 Continued

\begin{tabular}{|c|c|c|c|c|c|c|c|}
\hline Author & Date & Journal & $\begin{array}{l}\text { No of } \\
\text { studies }\end{array}$ & $\begin{array}{l}\text { No of } \\
\text { participants }\end{array}$ & Findings & $\begin{array}{l}\text { Risk of } \\
\text { bias }\end{array}$ & Grade \\
\hline $\begin{array}{l}\text { Konstantelias } \\
\text { et } a l^{61}\end{array}$ & 2017 & $\begin{array}{l}\text { Acta Chirurgica } \\
\text { Belgica } 2017\end{array}$ & $\begin{array}{l}30 \text { (19 RCTs } \\
\text { and } 11 \text { non- } \\
\text { RCTs) }\end{array}$ & 15385 & $\begin{array}{l}\text { Triclosan-coated sutures significantly } \\
\text { reduced risk of SSI compared with } \\
\text { standard suture. RR } 0.68 \text { ( } 95 \% \mathrm{CI} \\
0.57 \text { to } 0.81) \text {. } \\
\text { Triclosan-coated sutures significantly } \\
\text { reduced risk of SSI in clean, clean- } \\
\text { contaminated and 'contaminated } \\
\text { surgery'. }\end{array}$ & $\begin{array}{l}\text { Not } \\
\text { included }\end{array}$ & $\begin{array}{l}\text { Not } \\
\text { included }\end{array}$ \\
\hline Henriksen et $a l^{60}$ & 2017 & Hernia & $\begin{array}{l}8 \text { (only } \\
\text { included } \\
\text { studies } \\
\text { reporting } \\
\text { abdominal } \\
\text { wall closure) }\end{array}$ & 3641 & $\begin{array}{l}\text { Triclosan-coated sutures significantly } \\
\text { reduced risk of SSI compared with } \\
\text { standard suture in abdominal wall } \\
\text { closure. OR } 0.67 \text { ( } 95 \% \mathrm{Cl} 0.46 \text { to } \\
0.98) \text {. }\end{array}$ & $\begin{array}{l}\text { Not } \\
\text { included }\end{array}$ & $\begin{array}{l}\text { Not } \\
\text { included }\end{array}$ \\
\hline
\end{tabular}

CDC, centre for disease control; RCTs, randomised controlled trials; RR, relative risk; SSIs, surgical site infections.

\section{Quality of evidence}

Using the GRADE criteria, the evidence was graded as 'moderate' quality. The reason for downgrading was due to study limitations. Studies had high risk of selection bias due to unclear randomisation and allocation methods. In addition, studies had a high risk of performance and detection bias due to issues with blinding of participants and outcome assessors. The body of evidence was not downgraded for inconsistency as there was narrow point estimates and low study heterogeneity $\left(\mathrm{I}^{2}=17 \%\right)$. There were no issues with indirectness or imprecision as the outcome measures used are directly aligned to the outcome measures of interest in this review. There were also a large number of participants included in this review with satisfactory event rate numbers. Our symmetrical funnel plot indicated no risk of publication bias. Given the quality of the evidence we are moderately confident in the effect estimate, the true effect is likely to be close to the estimate of the effect.

The strengths of this current review include the thorough and systematic nature of data collection. This review represents the most up to date review of the literature and is the largest review of RCTs to date, including 11957 patients from 25 RCTs. A recent RCT in elective hip and knee surgery included 2546 participants, the largest RCT to date in this subject. ${ }^{34}$ This review is the only review to include this important and well-conducted study. In addition, this systematic review only included peer-reviewed studies with published full texts. Previous meta-analyses have included conference abstracts which do not go through the same rigorous peer-review process as full journal publications and thus represent a potential danger to review quality. ${ }^{32}$ Furthermore, robust quality and risk of bias assessment is not possible with these abstract publications. ${ }^{64}$ A further strength of this review is the detailed and systematic quality assessments, along with robust Cochrane risk of bias assessments, of all included studies. ${ }^{36} 64$ As demonstrated in table 25 out of 11 reviews assessed risk of bias and 1 out of 11 reviews assessed the quality of evidence. A strength of this review is the inclusion of a thorough risk of bias and GRADE assessment. In addition, this new review included further detailed sub group analysis based on superficial versus deep surgical infections and based on type of surgery, for example, clean, clean-contaminated, contaminated and dirty surgery.

The main weakness of this review is the study population. The review includes procedures which were classed as clean, clean-contaminated, contaminated and dirty. These types of surgery would all have differing rates of SSI. The authors therefore performed a subanalyses of the different categories of surgery. Routine antibiotic prophylaxis was used in 15 studies $^{27113438394244-51}$ with a variation in the antibiotic agent used and the timing. This is a potential confounder for the frequency of SSI. ${ }^{65} \mathrm{~A}$ proportion of the included studies assessed patients with an underlying malignancy who may have been immunosuppressed. This influences the rate of SSI and is not accounted for in many of the included studies. ${ }^{66}$ Another weakness is the heterogeneity in the use of triclosancoated sutures. In some studies, triclosan was used for closure of all surgical layers, whereas in other studies triclosan-coated sutures were only used on the superficial layers. This study heterogeneity should be noted when interpreting the meta-analysis result. This review reports trials using CDC criteria for superficial site infections. It is important to note that a stitch abscess does not meet the criteria for a superficial site infections. Patients may present with a stitch abscess to healthcare professionals and undergo treatment. This study does not report the impact of triclosan-coated sutures on stitch abscesses.

Our review is the largest review of RCTs to date in terms of patient numbers and demonstrates clinical effectiveness of triclosan-coated sutures when compared with standard sutures when assessing SSI rate. SSIs have been shown to have a significant impact on patient 
quality of life, as well as an increased burden on healthcare providers in terms of resource allocation. The cost of triclosan sutures is variable; however, the cost of SSI to patients and healthcare providers is sizeable. ${ }^{10-12} \mathrm{~A}$ robust cost-analysis has not been performed, nevertheless, organisations should consider carefully whether they routinely use triclosan-coated sutures in light of these positive meta-analysis findings. This review also identified that triclosan-coated sutures significantly reduced the risk of SSIs in clean and contaminated surgery, therefore thoughtful consideration should be paid to whether they are routinely used in this patient population. The results demonstrate that triclosan-coated sutures may not be as effective in reducing SSI rate in 'clean-contaminated' and 'dirty' surgery. However, a potential explanation for dirty surgery is the low patient numbers included in this subgroup. This is a potential area of future research given the effectiveness of triclosan-coated sutures in 'clean' and 'contaminated' surgery.

\section{CONCLUSION}

This systematic review identified 25 RCTs examining the effect of triclosan in reducing incidence of SSI, compared with non-coated sutures. The subsequent meta-analysis included 11957 patient and revealed an overall a risk ratio of RR 0.73 (95\% CI 0.65 to 0.82 ) of developing SSI in favour of triclosan-coated sutures, thereby demonstrating a statistically significant lower risk of SSI following closure of a surgical wound with triclosancoated sutures. Further analysis has demonstrated that triclosan-coated sutures significantly reduced the risk of SSIs in clean and contaminated surgery. This study is in agreement with previous smaller and less robust reviews which have produced comparable results. This is the largest review of RCTs in terms of number of included studies and number of participants from RCTs to demonstrate the clinical effectiveness of triclosan-coated sutures. Further detailed cost-effectiveness is required to assess the economic benefit of implementing the use of these sutures. The evidence considered in this review suggests that triclosan-coated sutures are effective in reducing SSIs, the use should in particular be considered in clean and contaminated surgery.

Acknowledgements The authors would like to acknowledge Mr Andrew Sprowson for his initial work on this review. Mr Sprowson was an Orthopaedic surgeon and Associate Profressor who tragically died in a car accident on 13th March 2015. Andy was an exceptional supervisor and academic who is dearly missed by us all.

Contributors All authors contributed to the production of this manuscript and meet the ICMJE criteria. IA: conception of review, data collection, analysis and drafted final manuscript. AJB: data collection, analysis and drafted final manuscript. SR and WC: data analysis and revised final manuscript. ED: data collection and revision of final manuscript. NAS: revision of final manuscript. MR: conception of idea and revision of final manuscript.

Funding The authors have not declared a specific grant for this research from any funding agency in the public, commercial or not-for-profit sectors.

Competing interests None declared.

Patient consent for publication Not required.
Provenance and peer review Not commissioned; externally peer reviewed.

Data availability statement Data are available upon reasonable request.

Open access This is an open access article distributed in accordance with the Creative Commons Attribution Non Commercial (CC BY-NC 4.0) license, which permits others to distribute, remix, adapt, build upon this work non-commercially, and license their derivative works on different terms, provided the original work is properly cited, appropriate credit is given, any changes made indicated, and the use is non-commercial. See: http://creativecommons.org/licenses/by-nc/4.0/.

\section{REFERENCES}

1. Magill SS, Edwards JR, Bamberg W, et al. Multistate pointprevalence survey of health care-associated infections. N Engl J Med 2014;370:1198-208.

2. Mattavelli I, Rebora P, Doglietto G, et al. Multi-Center randomized controlled trial on the effect of triclosan-coated sutures on surgical site infection after colorectal surgery. Surg Infect 2015;16:226-35.

3. Leaper DJ. Surgical-Site infection. Br J Surg 2010;97:1601-2.

4. Hranjec T, Swenson BR, Sawyer RG. Surgical site infection prevention: how we do it. Surg Infect 2010;11:289-94.

5. Kurtz S, Ong K, Lau E, et al. Projections of primary and revision hip and knee arthroplasty in the United States from 2005 to 2030. J Bone Joint Surg Am 2007;89:780-5.

6. Chang WK, Srinivasa S, Morton R, et al. Triclosan-impregnated sutures to decrease surgical site infections: systematic review and meta-analysis of randomized trials. Ann Surg 2012;255:854-9.

7. Diener MK, Knebel P, Kieser M, et al. Effectiveness of triclosancoated PDS plus versus uncoated PDS II sutures for prevention of surgical site infection after abdominal wall closure: the randomised controlled PROUD trial. Lancet 2014;384:142-52.

8. de Lissovoy G, Fraeman K, Hutchins V, et al. Surgical site infection: incidence and impact on hospital utilization and treatment costs. Am $J$ Infect Control 2009;37:387-97.

9. Kirkland KB, Briggs JP, Trivette SL, et al. The impact of surgicalsite infections in the 1990s: attributable mortality, excess length of hospitalization, and extra costs. Infect Control Hosp Epidemiol 1999;20:725-30.

10. Namba RS, Inacio MCS, Paxton EW. Risk factors associated with surgical site infection in 30,491 primary total hip replacements. J Bone Joint Surg Br 2012;94:1330-8.

11. Nakamura T, Kashimura N, Noji T, et al. Triclosan-Coated sutures reduce the incidence of wound infections and the costs after colorectal surgery: a randomized controlled trial. Surgery 2013;153:576-83.

12. Fleck T, Moidl R, Blacky A, et al. Triclosan-Coated sutures for the reduction of sternal wound infections: economic considerations. Ann Thorac Surg 2007;84:232-6.

13. Neumayer L, Hosokawa P, Itani K, et al. Multivariable predictors of postoperative surgical site infection after general and vascular surgery: results from the patient safety in surgery study. J Am Coll Surg 2007;204:1178-87.

14. Malone DL, Genuit T, Tracy JK, et al. Surgical site infections: reanalysis of risk factors. J Surg Res 2002;103:89-95.

15. Cheadle WG. Risk factors for surgical site infection. Surg Infect 2006;7(Suppl 1):s7-11.

16. Katz S, Izhar M, Mirelman D. Bacterial adherence to surgical sutures. A possible factor in suture induced infection. Ann Surg 1981;194:35-41.

17. Gristina AG, Price JL, Hobgood CD, et al. Bacterial colonization of percutaneous sutures. Surgery 1985;98:12-19.

18. Kathju S, Nistico L, Hall-Stoodley L, et al. Chronic surgical site infection due to suture-associated polymicrobial biofilm. Surg Infect 2009;10:457-61.

19. Kathju S, Nistico L, Lasko L-A, et al. Bacterial biofilm on monofilament suture and porcine xenograft after inguinal herniorrhaphy. FEMS Immunol Med Microbiol 2010;59:405-9.

20. Kathju S, Nistico L, Tower I, et al. Bacterial biofilms on implanted suture material are a cause of surgical site infection. Surg Infect 2014;15:592-600.

21. Darouiche RO, Meade R, Mansouri M, et al. In vivo efficacy of antimicrobial-coated fabric from prosthetic heart valve sewing rings. $J$ Heart Valve Dis 1998;7:639-46.

22. Blaker JJ, Nazhat SN, Boccaccini AR. Development and characterisation of silver-doped bioactive glass-coated sutures for tissue engineering and wound healing applications. Biomaterials 2004;25:1319-29.

23. Storch ML, Rothenburger SJ, Jacinto G. Experimental efficacy study of coated Vicryl plus antibacterial suture in guinea pigs challenged with Staphylococcus aureus. Surg Infect 2004;5:281-8. 
24. Ming X, Rothenburger S, Nichols MM. In vivo and in vitro antibacterial efficacy of PDS plus (polidioxanone with triclosan) suture. Surg Infect 2008;9:451-7.

25. Rothenburger S, Spangler D, Bhende S, et al. In vitro antimicrobial evaluation of coated VICRYL* plus antibacterial suture (coated polyglactin 910 with triclosan) using zone of inhibition assays. Surg Infect 2002;3(Suppl 1):s79-87.

26. Marco F, Vallez R, Gonzalez P, et al. Study of the efficacy of coated Vicryl plus antibacterial suture in an animal model of orthopedic surgery. Surg Infect 2007;8:359-66.

27. Wang ZX, Jiang CP, Cao Y, et al. Systematic review and metaanalysis of triclosan-coated sutures for the prevention of surgical-site infection. Br J Surg 2013;100:465-73.

28. Edmiston CE, Daoud FC, Leaper D. Is there an evidence-based argument for embracing an antimicrobial (triclosan)-coated suture technology to reduce the risk for surgical-site infections?: A metaanalysis. Surgery 2013;154:89-100.

29. Sajid MS, Craciunas L, Sains $P$, et al. Use of antibacterial sutures for skin closure in controlling surgical site infections: a systematic review of published randomized, controlled trials. Gastroenterol Rep 2013;1:42-50.

30. Daoud FC, Edmiston CE, Leaper D. Meta-Analysis of prevention of surgical site infections following incision closure with triclosancoated sutures: robustness to new evidence. Surg Infect 2014;15:165-81.

31. Guo J, Pan L-H, Li Y-X, et al. Efficacy of triclosan-coated sutures for reducing risk of surgical site infection in adults: a meta-analysis of randomized clinical trials. J Surg Res 2016;201:105-17.

32. de Jonge SW, Atema JJ, Solomkin JS, et al. Meta-Analysis and trial sequential analysis of triclosan-coated sutures for the prevention of surgical-site infection. Br J Surg 2017;104:e118-33.

33. Renko M, Paalanne N, Tapiainen T, et al. Triclosan-containing sutures versus ordinary sutures for reducing surgical site infections in children: a double-blind, randomised controlled trial. Lancet Infect Dis 2017;17:50-7.

34. SprowsonAP, Jensen C, Parsons N, et al. The effect of triclosancoated sutures on the rate of surgical site infection after hip and knee arthroplasty: a double-blind randomized controlled trial of 2546 patients. Bone Joint J 2018;100-B:296-302.

35. Moher D, Liberati A, Tetzlaff J, et al. Preferred reporting items for systematic reviews and meta-analyses: the PRISMA statement. PLoS Med 2009;6:e1000097.

36. Green S, Higgins J. Cochrane Handbook for systematic reviews of interventions 2005. Version.

37. Guyatt GH, Oxman AD, Vist GE, et al. Grade: an emerging consensus on rating quality of evidence and strength of recommendations. $B M J$ 2008;336:924-6.

38. Baracs J, Huszár O, Sajjadi SG, et al. Surgical site infections after abdominal closure in colorectal surgery using triclosan-coated absorbable suture (PDS plus) vs. uncoated sutures (PDS II): a randomized multicenter study. Surg Infect 2011;12:483-9.

39. Chen SY, Chen TM, Dai NT, et al. Do antibacterial-coated sutures reduce wound infection in head and neck cancer reconstruction? Eur J Surg Oncol 2011;37:300-4.

40. Ford HR, Jones P, Gaines B, et al. Intraoperative handling and wound healing: controlled clinical trial comparing coated Vicryl plus antibacterial suture (coated polyglactin 910 suture with triclosan) with coated Vicryl suture (coated polyglactin 910 suture). Surg Infect 2005;6:313-21.

41. Galal I, El-Hindawy K. Impact of using triclosan-antibacterial sutures on incidence of surgical site infection. Am J Surg 2011;202:133-8.

42. Ichida K, Noda H, Kikugawa R, et al. Effect of triclosan-coated sutures on the incidence of surgical site infection after abdominal wall closure in gastroenterological surgery: a double-blind, randomized controlled trial in a single center. Surgery 2018. doi:10.1016/j.surg.2017.12.020. [Epub ahead of print: 10 Mar 2018].

43. Isik I, Selimen D, Senay S, et al. Efficiency of antibacterial suture material in cardiac surgery: a double-blind randomized prospective study. Heart Surg Forum 2012;15:40-5.

44. Justinger C, Slotta JE, Ningel S, et al. Surgical-Site infection after abdominal wall closure with triclosan-impregnated polydioxanone sutures: results of a randomized clinical pathway facilitated trial (NCT00998907). Surgery 2013;154:589-95

45. Karip AB, Çelik K, Aydın T, et al. Effect of triclosan-coated suture and antibiotic prophylaxis on infection and recurrence after Karydakis flap repair for pilonidal disease: a randomized Parallel-Arm doubleblinded clinical trial. Surg Infect 2016;17:583-8.

46. Mingmalairak C, Ungbhakorn P, Paocharoen V. Efficacy of antimicrobial coating suture coated polyglactin 910 with tricosan
(Vicryl plus) compared with polyglactin 910 (Vicryl) in reduced surgical site infection of appendicitis, double blind randomized control trial, preliminary safety report. J Med Assoc Thai 2009;92:770-5.

47. Rasić Z, Schwarz D, Adam VN, et al. Efficacy of antimicrobial triclosan-coated polyglactin 910 (Vicryl* plus) suture for closure of the abdominal wall after colorectal surgery. Coll Antropol 2011;35:439-43.

48. Ruiz-Tovar J, Alonso N, Morales V, et al. Association between triclosan-coated sutures for abdominal wall closure and incisiona surgical site infection after open surgery in patients presenting with fecal peritonitis: a randomized clinical trial. Surg Infect 2015;16:588-94.

49. Seim BE, Tønnessen T, Woldbaek PR. Triclosan-Coated sutures do not reduce leg wound infections after coronary artery bypass grafting. Interact Cardiovasc Thorac Surg 2012;15:411-5.

50. Thimour-Bergström L, Roman-Emanuel C, Scherstén $\mathrm{H}$, et al. Triclosan-Coated sutures reduce surgical site infection after open vein harvesting in coronary artery bypass grafting patients: a randomized controlled trial. Eur J Cardiothorac Surg 2013;44:931-8.

51. Turtiainen J, Saimanen EIT, Mäkinen KT, et al. Effect of triclosancoated sutures on the incidence of surgical wound infection after lower limb revascularization surgery: a randomized controlled trial. World J Surg 2012;36:2528-34.

52. Williams N, Sweetland H, Goyal S, et al. Randomized trial of antimicrobial-coated sutures to prevent surgical site infection after breast cancer surgery. Surg Infect 2011;12:469-74.

53. Zhang Z-T, Zhang H-W, Fang X-D, et al. Cosmetic outcome and surgical site infection rates of antibacterial absorbable (polyglactin 910) suture compared to Chinese silk suture in breast cancer surgery: a randomized pilot research. Chin Med J 2011;124:719-24.

54. Tabrizi R, Mohajerani H, Bozorgmehr F. Polyglactin 910 suture compared with polyglactin 910 coated with triclosan in dental implant surgery: randomized clinical trial. Int J Oral Maxillofac Surg 2019. doi:10.1016/j.ijom.2019.01.011. [Epub ahead of print: 06 Feb 2019].

55. Roy PK, Kalita P, Lalhlenmawia H, et al. Comparison of surgical site infection rate between antibacterial coated surgical suture and conventional suture: a randomized controlled single centre study for preventive measure of postoperative infection. International Journal of Pharmaceutical Sciences and Research 2019;10:2385-91.

56. Lin S-J, Chang F-C, Huang T-W, et al. Temporal change of interleukin-6, C-reactive protein, and skin temperature after total knee arthroplasty using triclosan-coated sutures. Biomed Res Int 2018;2018:9.

57. Arslan NC, Atasoy G, Altintas T, et al. Effect of triclosan-coated sutures on surgical site infections in pilonidal disease: prospective randomized study. Int J Colorectal Dis 2018;33:1445-52.

58. Apisarnthanarak A, Singh N, Bandong AN, et al. Triclosan-Coated sutures reduce the risk of surgical site infections: a systematic review and meta-analysis. Infect Control Hosp Epidemiol 2015;36:169-79.

59. Wu X, Kubilay NZ, Ren J, et al. Antimicrobial-coated sutures to decrease surgical site infections: a systematic review and metaanalysis. Eur J Clin Microbiol Infect Dis 2017;36:19-32.

60. Henriksen NA, Deerenberg EB, Venclauskas L, et al. TriclosanCoated sutures and surgical site infection in abdominal surgery: the TRISTAN review, meta-analysis and trial sequential analysis. Hernia 2017;21:833-41.

61. Konstantelias AA, Andriakopoulou CSI, Mourgela S. TriclosanCoated sutures for the prevention of surgical-site infections: a metaanalysis. Acta Chir Belg 2017;117:137-48.

62. Leaper DJ, Edmiston CE, Holy CE. Meta-Analysis of the potential economic impact following introduction of absorbable antimicrobial sutures. Br J Surg 2017;104:e134-44.

63. Sandini M, Mattavelli I, Nespoli L, et al. Systematic review and meta-analysis of sutures coated with triclosan for the prevention of surgical site infection after elective colorectal surgery according to the PRISMA statement. Medicine 2016;95:e4057.

64. Higgins JPT, Altman DG, Gøtzsche PC, et al. The Cochrane collaboration's tool for assessing risk of bias in randomised trials. BMJ 2011;343:d5928.

65. Hawn MT, Richman JS, Vick CC, et al. Timing of surgical antibiotic prophylaxis and the risk of surgical site infection. JAMA Surg 2013;148:649-57.

66. Blam OG, Vaccaro AR, Vanichkachorn JS, et al. Risk factors for surgical site infection in the patient with spinal injury. Spine 2003;28:1475-80. 